\title{
Desarrollo comunitario en El Salvador
}

Aquiles Montoya

Con el presente trabajo, buscamos nuevamente aproximarnos a esa realidad que denominamos nueva economía popular, desarrollo comunitario, o economía asociativa y autogestionaria, como otros le llaman. En verdad, se trata de un estudio de 51 comunidades de las más de 300 que atiende la Asociación de Comunidades Rurales para el Desarrollo de El Salvador (CRIPDES), y gracias a cuyo apoyo fue posible llevar a feliz término este esfuerzo, en tanto nos facilitó nombres, ubicaciones y contactos para realizar la investigación. Nosotros en la cátedra organizamos a los estudiantes en grupos de cinco y procedimos a sortear los nombres de las comunidades entre los diferentes grupos.

Del total de 51 comunidades estudiadas en cinco departamentos del país: La Libertad, en los municipios de Tamanique (3), Tacachico (3), Chiltiupán (1), Comasagua (4), San Salvador (8) Chalatenango, (8) Cuscatlán, municipio de Suchitoto (12) y San Vicente, municipio de Tecoluca, (12), algunas como las de Chalatenango y particularmente: Arcatao, San José Las Flores, Nueva Trinidad y San Isidro Labrador son municipios que cuentan con sus consejos municipales y un considerable número de familias, pero conservan una excelente organización comunitaria. El universo estudiado incluye un aproximado de 5,368 familias, distribuidas de la siguiente manera: Cuscatlán: 1,020,

Desarrollo comunitario en El Salvador 
Chalatenango: 2,200, San Vicente: 1002, San Salvador: 196 y La Libertad: 950.

El trabajo, en parte, es una síntesis de las investigaciones de campo realizadas por 300 estudiantes de los dos cursos de Desarrollo Económico, quienes trabajaron en base a una guía metodológica proporcionada por nosotros, la cual se presenta como un anexo, posteriormente recabaron la información con informantes calificados y/o con encuestas que corrieron entre los integrantes de las comunidades, la cual fue procesada y les permitió elaborar un estudio para cada comunidad. Esos estudios constituyen la materia prima de este trabajo.

La experiencia investigativa en las comunidades ha brindado el beneficio adicional de que los estudiantes de las carreras de administración de empresas, contaduría y economía, tuvieran una aproximación con la realidad comunitaria y rural de nuestro país. Que observaran con sus propios ojos las múltiples carencias que se padecen en el campo y de qué manera los pobres, cuando se organizan van dándole respuesta a sus problemas, gracias al apoyo de ONG y donantes extranjeros. Por los comentarios recibidos, creo, que en su gran mayoría los estudiantes han quedado satisfechos con la tarea asignada, mucho les ha impresionado el trato cordial de estas familias, su espíritu solidario y su confianza en que con su esfuerzo están construyendo algo nuevo y diferente. Algunos, de mayor sensibilidad, se han comprometido a colaborar con la comunidad que visitaron y casi todos los grupos incluyen en sus recomendaciones que la UCA apoye a estas comunidades a través del servicio social que deben realizar los estudiantes. Ciertamente hubo algunos temores iniciales y algunas dificultades en cuanto al acceso a más de alguna comunidad; sin embargo, todo se superó y en sus mentes, así como en los muchos registros fotográficos que realizaron, guardarán esta experiencia quizá por muchos años.

La síntesis de los 51 estudios elaborados por los estudiantes nos ha permitido conocer algunos de los logros más importantes alcanzados por estas comunidades, así como nos permitirá ofrecer algunas sugerencias a fin de que continúen con su proceso de desarrollo. Adicionalmente, nos permite reafirmar una vieja hipótesis cual es que la organización de las comunidades es la premisa fundamental para avanzar por el camino hacia el desarrollo. 


\section{Características de las comunidades estudiadas:}

Para poder realizar un análisis objetivo de las comunidades y, a su vez, para que el mismo resulte comprensible para quienes no tienen conocimiento de esta nueva realidad que se está desarrollando en nuestro país y en muchos otros del mundo, lo mismo que de la realidad rural en nuestro país, es preciso, previamente, realizar una breve caracterización de las mismas y señalar algunos rasgos de la vida rural.

- Seguramente, lo primero que debemos establecer es qué entendemos por una comunidad, ya que si bien toda comunidad es un asentamiento humano, no todo asentamiento humano es una comunidad. Una comunidad exige cierto nivel o grado de organización, sin la cual no puede funcionar como un todo. Pero a su vez exige de la realización de ciertas actividades sociales y, principalmente, económicas en común. La existencia de propiedad comunitaria, no de manera exclusiva pero si de manera importante. Pero sobre todo la práctica de valores solidarios, unitarios, comunitarios, de cooperación, de fraternidad, de esperanza. Estos serían a nuestro juicio los rasgos que nos indican si nos encontramos ante una comunidad o ante un simple asentamiento humano.

- Se trata de unidades heterogéneas, tanto en su origen como en cuanto a sus integrantes, así como al tiempo de venir funcionando y a su nivel de desarrollo. Así, encontramos comunidades que se constituyeron a finales de la década de los ochenta, otras, en cambio, luego de los acuerdos de paz, década de los noventa y algunas, tan recientes, como luego de los terremotos, al inicio del nuevo siglo.

Algunas se integraron como resultado de repatriaciones; otras, en cambio, como repoblaciones y fruto de la desmovilización de excombatientes, las segundas, y las terceras con familias damnificadas. Sin embargo, las primeras y las segundas, en la actualidad, tienen una combinación de integrantes: repatriados, repobladores y desmovilizados. Aunque siempre sea posible encontrar más de alguna con sólo alguno de sus componentes. Sólo desmovilizados, por ejemplo. También hemos podido detectar otras comunidades que no encajan dentro de los tres primeros grupos, se trata de comunidades creadas como fruto del proceso de reforma agraria y otras que son meros asentamientos humanos y que no cuentan con tierra para trabajar. 
Es importante destacar lo anterior en tanto que en el caso de los repatriados se trataba de una población que ya gozaba de un fuerte grado de organización en el exilio, así como de una práctica de vida comunitaria con todo lo que ello implica en términos de valores, tales como: cooperación, unidad, solidaridad, etc.

- Otro elemento importante a tener presente es que se trata de comunidades rurales, cuya reproducción material y espiritual está estrechamente vinculada a la tierra. Se trata, pues, de familias campesinas, y hablar de campesinos en el país, significa que se trata de familias que no cuentan con agua potable, ni con viviendas dignas; con graves problemas de acceso a servicios de salud y de educación, e inclusive, a energía eléctrica, así como también con serios problemas para comunicarse dado el pésimo estado de los caminos vecinales. Y lo que es más serio aún se trata de familias que no gozan de un empleo permanente, ya que su ocupación está determinada por el carácter estacional de sus cultivos.

- También es importante señalar que existe cierta correlación entre el nivel de desarrollo de las comunidades y el gobierno municipal. Cuando los gobiernos municipales son del FMLN, existe un mayor apoyo al desarrollo comunitario, esto lo hemos podido observar en las comunidades de Chalatenango, como también en las del Paisnal, Suchitoto y Tecoluca. En cambio, las comunidades ubicadas en Comasagua o Tamanique, donde el gobierno municipal es de ARENA tienen mayores carencias y el apoyo municipal es prácticamente nulo; sin embargo, también influye è tiempo de vida organizada de la comunidad, así como la naturaleza de la misma.

\section{Logros o beneficios alcanzados.}

2.1. Los miembros de las comunidades cuentan con una excelente organización y con un elevado grado de participación en las diferentes actividades que han emprendido, así como en la realización de numerosas propuestas y proyectos los cuales se deciden en asambleas generales. Si algo excelente está ocurriendo en las comunidades organizadas, esto es, la participación democrática de las personas, lo cual ciertamente es una realidad inédita y que convierte a tales experiencias en gérmenes de una nueva forma de vida y consecuentemente de una nueva sociedad. Es destacable también la fuerte participación de las mujeres. 
La organización con que cuentan es bastante sencilla, aunque muy funcional. Poseen una directiva y algunos comités, como los de mujeres, jóvenes o pastoral, u otros dependiendo de las necesidades, tales como comité de comercialización, comité de agua, etc. La máxima instancia es la asamblea general en la cual se deciden las cuestiones trascendentes.

La organización a dado lugar a obtener una personería jurídica en tanto que Asociación Comunitaria, la cual es de suma importancia para la gestión de recursos, presentar proyectos o efectuar demandas a los gobiernos municipales o al gobierno central.

2.2. Además de la organización a nivel de comunidad, las diferentes comunidades están organizadas regionalmente. Así encontramos a UCRES, organización de comunidades del norte de los departamentos de San Salvador y de La Libertad; CCRCH, comunidades de Chalatenango; PROGRESO, comunidades en el departamento de Cuscatlán; CODESMA, en la zona sur del departamento de La Libertad; CDR, en el departamento de San Vicente.

2.3. En cada una de las cinco regiones anteriormente señaladas, se cuenta con una cooperativa de ahorro y crédito que busca atender las necesidades de financiamiento de las diferentes familias de la región. Las juntas directivas y los comités de vigilancia de las cooperativas están integradas por representantes de las diferentes comunidades de cada región, además de otras iniciativas crediticias como los bancos comunales.

2.4. La casi totalidad de comunidades posee activos que son de su propiedad, ya sea como comunidades en sí, o bien como grupos familiares. Así, cuentan con tierra, viviendas, escuelas, clínicas, guarderías, servicio de agua potable, casas comunales, tendidos eléctricos, etc. $\mathrm{Y}$ alguna maquinaria o equipo motorizado.

En la gran mayoría de comunidades, la casi totalidad de viviendas se encuentran en buenas condiciones, de igual manera cuentan con servicio de agua potable y energía eléctrica. Si bien cuentan con centros educativos a nivel básico, cuyas construcciones son de su propiedad, en muchos casos el gobierno no asume la responsabilidad de pagar a los profesores o de ir ampliando los centros educativos a medida que los niños y jóvenes ascienden en su proceso educativo. En materia de salud, la casi totalidad de comunidades tienen un botiquín, 
muchas poseen un local para la clínica, pero las visitas de los médicos son demasiado espaciadas: una vez al mes. No obstante es común encontrar promotores de salud que atienden problemas sencillos de salud o de salubridad.

El pago por agua potable, cuando es propiedad de la comunidad, se reduce a una cuota muy baja, la cual se destina a un fondo que sirve para darle mantenimiento al servicio. En algunas comunidades que poseen guarderías, además del cuidado de los niños se les da alimentación y control médico, por una módica cuota de diez colones al mes, lo cual posibilita que las madres puedan desempeñar sus actividades económicas o de otro tipo, sin que ello signifique una prolongación o doble jornada laboral de las mujeres o bien, que no puedan hacer más que cuidar a los hijos.

Las viviendas, en general, cuentan con patios grandes donde es posible cultivar algunas hortalizas o tener algunos animales domésticos que cumplen una función de ahorro dentro de la economía familiar.

2.5. La participación organizada de la mujer y de los jóvenes, es también un logro inestimable, ya que lo primero permite ir superando las estructuras machistas tan acendradas en el campo y lo segundo permite que la juventud se desarrolle sana y practicando los nuevos valores comunitarios. En la mayoría de comunidades de mayor desarrollo es posible observar dentro de las estructuras organizativas los comités de mujeres y jóvenes. Así como también formando parte de las juntas directivas comunitarias.

La realidad anterior ha conducido a que en Arcatao, por ejemplo, existan dos bancos comunales, y que uno de ellos sea manejado y funcione exclusivamente para las mujeres. También es posible observar como los jóvenes y los niños se dedican a la limpieza de sus comunidades y a la reforestación; existe una comunidad en la cual a cada niño se le asigna un arbolito recién sembrado y el niño será el responsable de que no se seque, para ello deberá regarlo durante el verano. Esto ocurre en la comunidad Rutilio Grande, ejemplo que debería de replicarse en todas las comunidades.

2.6. El surgimiento de formas asociativas en lo económico, es un avance de mucha significación para caminar hacia el desarrollo de las comunidades organizadas. Ya no se trata de tan sólo organizarse para construir una escuela, una casa comunal, o conseguir una donación 
que permita introducir agua potable o el tendido eléctrico. Así, es posible encontrar en varias comunidades cooperativas, tiendas comunales, comedores comunales, talleres comunales de bordados, panadería, carpintería y sastrería, etc. que además de promover la enseñanza de oficios en forma sistemática, también se producen bienes para ser comercializados.

La asociatividad también se da en la comercialización de la producción agrícola, lo cual posibilita mejores precios de venta, desafortunadamente esta es una experiencia poco generalizada. O contar con su propio abastecimiento de agua potable con tarifas bajas, ya que esta oscila entre 5 y 25 colones mensuales, los cuales la comunidad puede destinar a diferentes fines sociales o económicos. Los anteriores son ejemplos observados en Arcatao y Nueva Trinidad.

2.7. La práctica de valores comunitarios como la unidad, la solidaridad, la cooperación, etc. Ejemplo de ello lo observamos en la comunidad Carasque, perteneciente al cantón del mismo nombre, en el municipio de Nueva Trinidad, donde la comunidad apoya a las viudas y a las madres solteras, donde se tiene un Centro de Bienestar Infantil, donde los niños además de cuidados reciben tres tiempos de comida y un refrigerio, pagando tan sólo diez colones al mes. Como también el hecho de que aquellos migrantes en Estados Unidos, organizados en la ciudad de Washington, envíen cada mes a la directiva de la comunidad 130 dólares para que ésta los asigne a la familia más necesitada. Y no deja de ser sorprendente también que esta pequeña comunidad de Carasque, cuente con un Centro de Computación, atendido por los profesores de la escuela y que los jóvenes puedan ser capacitados en el manejo de estos equipos por tan sólo uno cincuenta de colón la hora, el cual se usa para el mantenimiento del equipo. O el hecho de contar con Días Comunales. Los días sábados varias de las comunidades del nororiente de Chalatenango lo dedican a trabajos de beneficio a la comunidad como la reforestación, el arreglo y limpieza de calles, o la reparación de viviendas de mujeres viudas o madres solteras.

2.8. La posibilidad de llevar adelante sus proyectos e iniciativas, porque no se trata de esfuerzos individuales o aislados, sino de proyectos comunitarios que cuentan con el apoyo de las ONG así por ejemplo, esta misma comunidad de Carasque proyecta exportar bordados y café procesado a los EE.UU., aprovechando a su vez, el con- 
tacto que poseen con amigos y parientes que emigraron a los Estados Unidos. $\mathrm{O}$ el proyecto de frutas deshidratadas de Arcatao y Guarjila, que abre una nueva oportunidad en términos de empleo y de ingresos para estas comunidades rurales. O bien la planta procesadora de leche en San Carlos que ya es una realidad.

2.9. El avance hacia prácticas ecológicas como las observadas en Nueva Trinidad y otras muchas comunidades de Suchitoto, donde usan abono orgánico, barreras vivas y muertas para la conservación del suelo, donde practican la reforestación y a su vez tienen reservadas algunas manzanas como reservas ecológicas, esto último, principalmente en las comunidades de Chalatenango y Suchitoto o bien, en la comunidad Guajoyo, donde se cuentan con 250 manzanas de reserva ecológica.

2.10. La ausencia de delincuencia, drogadicción y maras, al interior de las comunidades. $\mathrm{Y}$ los niveles muy bajos y hasta puntuales en términos de alcoholismo.

2.11. Los avances hacia actividades manufactureras: calzado, confecciones y bordados, artesanías, carpinterías, metal mecánica, etc. como se observa en algunas comunidades de Chalatenango, tales como Los Ranchos, Arcatao, Las Flores, etc.

2.12. Los proyectos innovadores: como la deshidratación de frutas, o la producción de gas metano a partir del estiércol de cerdos en San Antonio Los Ranchos o el Hotelito Armonía en la misma localidad, administrado por una cooperativa de jóvenes o el centro turístico en la comunidad Las Américas o el procesamiento de leche a nivel industrial en San Carlos, donde también se procesa y exporta semilla de marañón y maní. $\mathrm{O}$ la producción de medicamentos de origen vegetal en la comunidad Rutilio Grande o las cocinas solares, o el cultivo de camarón de agua dulce en la comunidad Las Américas, etc.

2.13. La gran mayoría de las comunidades cuenta con viviendas dignas, con servicios de energía eléctrica, de agua potable y centros educativos. Ahora bien estos servicios los han obtenido gracias a sus gestiones ante donantes extranjeros. En algunas comunidades el gobierno paga a los maestros, en otras son las mismas comunidades o las alcaldías quienes cargan con tales costos. Solamente en una minoría de las comunidades se cuenta con servicios de salud, aunque son muchas las comunidades que cuentan con algún local que fue construido con 
la idea de tener su propia unidad de salud. Algunas comunidades cuentan con promotores de salud, pero la gran mayoría sólo reciben visitas mensuales de médicos.

2.14. La gran mayoría de los integrantes de las comunidades poseen tierras para realizar sus actividades agropecuarias; sin embargo, dado el carácter deprimido de los precios de los productos agrícolas en general, resulta imposible que puedan seguir avanzando en su desarrollo, mientras no realicen algunas modificaciones en sus prácticas agrícolas. Nos da la impresión que si bien estas comunidades organizadas, en muchos aspectos tienen mejores condiciones de vida que el promedio de las familias campesinas, en lo que a su actividad económica se refiere, aún no logran diferenciarse mucho del campesinado tradicional y no están aprovechando suficientemente las ventajas de tener acceso a la tierra y el contar con una excelente organización que podría usarse con fines económicos.

2.15. Algo que a simple vista no es muy importante para quienes tenemos asegurada la alimentación es que la casi totalidad de comunidades han conseguido su seguridad alimentaria y que avanzan hacia la consecución de una agricultura orgánica, buscando preservar el medio ambiente. En muchas comunidades ya no se practican las quemas, se comprende la importancia de preservar y ampliar la cubierta arbórea, así como evitar la erosión para lo cual crean barreras vivas y muertas.

2.16. Otro logro que está presente en las comunidades es la preservación de la memoria histórica, ya sea de manera oral, mediante la conversación de los mayores con los niños o jóvenes, o por medio de canciones o representaciones teatrales, como también a través de monumentos testimonios como la casa destruida que se encuentra en la comunidad Ellacuría, donde, a la par de un mural de un helicóptero ametrallando a la población, se encuentran los restos de un molino de nixtamal destrozado, así como unas cuantas cruces en memoria de algunos de los caídos. También es posible observar los recuerdos de la guerra en el Museo de la Revolución en la comunidad La Sabana o los muchos murales observables en diferentes comunidades. Así como la celebración de muchos aniversarios de masacres en varias comunidades de Suchitoto.

2.17. Los integrantes de las comunidades son optimistas y preservan la esperanza de que otro mundo es posible y que construirlo de- 
pende en mucho de su esfuerzo, de su trabajo, de su sacrificio...Pero el microcosmos que están construyendo para sus hijos, será mucho mejor que aquel en el cual ellos crecieron.

\section{Conclusiones}

3.1 La primera conclusión a que es posible llegar, a partir de las comunidades estudiadas, es que la organización comunitaria y la participación de las comunidades en pos de su desarrollo económico y social, funciona. Afirmamos lo anterior por dos razones fundamentalmente o la primera es que en la mayoría de comunidades, la mayoría de personas han afirmado que sus condiciones de vida han mejorado, lo cual resulta obvio, si tenemos en cuenta la cantidad de logros o beneficios alcanzados. Y la segunda razón es que comunidades que se crean a mediados de la década de los 80 siguen funcionando y fortaleciéndose, si la organización y la participación comunitaria no funcionaran ya tiempos se hubiesen desintegrado. $Y$ esto adquiere un mayor significado cuando vivimos en un mundo casi dominado por el individualismo, por el egoísmo, por el sálvese quien pueda.

3.2 Que los pobres, cuando están organizados, son capaces de dar respuesta a sus necesidades familiares y sociales: alimentación, vivienda, agua potable, energía eléctrica, salud y educación. Es importante destacar el significado de lo anterior, se trata de que los pobres logran un rol protagónico, que son ellos sujetos activos en su proceso de desarrollo y no actores, que sencillamente asumen de manera pasiva un rol que les asigna el Banco Mundial o el gobierno. Que necesitan ayuda, sí. Porque son pobres, pero no inválidos.

3.3 Que si tienen acceso a activos, son capaces de hacer sostenible su desarrollo en términos sociales, económicos y ambientales. No se trata, como algunos creen, que si estas comunidades sobreviven es gracias al asistencialismo, pero que de hecho se han acostumbrado a vivir de lo que les dan y que sin la ayuda internacional desaparecerían en un abrir y cerrar de ojos. Los integrantes de las comunidades viven de su trabajo, la ayuda recibida no es para satisfacer sus necesidades alimenticias o de vestido, sino que consiste en infraestructura o en activos físicos. Mantienen escuelas funcionando, inclusive, cuando el gobierno no ayuda; han creado, inclusive, sistemas solidarios de salud, cual es el caso de Guarjila, donde con un aporte mensual de 15 colo- 
nes por familia, se tiene acceso a servicio médico y a medicinas. Existe conciencia y preocupación por realizar prácticas de cultivo ecológicas y labores de reforestación.

3.4 Que el protagonismo y la participación organizada de los pobres evidencia su capacidad de salir de la miseria y que es el mejor antídoto ante la pobreza y la exclusión que genera el sistema capitalista. En un mundo donde cunde la desesperanza, donde sencillamente observamos cómo día tras día se incrementan los problemas sociales, económicos, ambientales, etc., sin saber qué hacer, las comunidades organizadas nos están brindando numerosos ejemplos de qué hacer, de cómo hacerlo y para qué hacerlo. Los gérmenes de la nueva sociedad se están incubando en las comunidades organizadas: allí observamos nuevos valores, una nueva actitud ante la vida, una nueva forma de vivir y de trabajar. En las comunidades no se respira ese aire loco de tener por tener y de tener cada día más. No se es por lo que se tiene, sino por lo que se da. Ningún cargo en la organización de las comunidades es remunerado, además de ser directivo, hay que trabajar para vivir.

3.5 Que este es el camino correcto hacia la superación de los problemas típicos de los países subdesarrollados, lo atestigua la existencia de cientos de comunidades organizadas en nuestro país que han visto mejorar sus condiciones de vida y de trabajo, de las cuales esta investigación es tan sólo una muestra. $Y$ cuya mayor riqueza, como lo he repetido infinidad de veces, no radica sólo en lo logrado, sino en sus enormes potencialidades para lograr mucho más.

No quisiera concluir este apartado sin antes realizar una aclaración a fin de no parecer un ingenuo o un necio, se que existen problemas en las comunidades, en unas más que en otras menos, pero esos problemas que en algunas aún existen en otras de mayor desarrollo ya han sido superados y otros, que aún existen en las comunidades de mayor desarrollo son perfectamente superables, ya que no se originan en la naturaleza misma del desarrollo comunitario, no son problemas congénitos. Tan consciente estoy de lo anterior que, precisamente, por eso es que a continuación propongo una serie de medidas y acciones que, a mi juicio, pueden contribuir a resolver algunos problemas y consecuentemente a hacer avanzar el desarrollo comunitario. 
Por otra parte, si insisto más en los aspectos positivos, si los destaco e, inclusive, si tiendo a extrapolar logros de una o unas cuantas comunidades a todo el sector comunitario es porque me parece que son las posibilidades o potencialidades que tiene el desarrollo comunitario en tanto que "modelo" de desarrollo.

Adicionalmente, se trata de una realidad que en nuestro medio, o no se conoce, o se ha visto como algo marginal o, que sencillamente, se desprecia, porque no se trata de un modelo teórico que cuenta con toda una fundamentación econométrica; sin embargo, el desarrollo comunitario es una realidad que está siendo implementada día tras día por los pobres, por los excluidos, por las mayorías populares del campo y que busca dar una respuesta integral a los males y problemas generados por el sistema capitalista y agudizados por la implementación de las medidas neoliberales. El desarrollo comunitario, me atrevería a sostener, que, sin que sus sujetos tengan conciencia de ello, es una objetivación de la civilización de la pobreza de que hablaba el padre Ellacuría, o de la visión del socialismo humanista con que soñaba el Che. Tenemos, pues, frente a nosotros los gérmenes de una nueva sociedad y para quienes no estamos a favor del capitalismo esto es de suma importancia y trascendencia.

\section{Recomendaciones.}

Si bien la mayoría de los miembros de las comunidades trabajan en sus propias actividades, éstas siguen siendo agrícolas en su mayoría, aunque se dan algunos casos de actividades pecuarias, manufactureras, e inclusive, algunas agroindustriales como la planta procesadora de leche o la procesadora de semilla de marañón y maní en la comunidad San Carlos o la producción de vino de marañón en la comunidad Monte Cristo. También existe una pequeña planta que procesa y envasa medicamentos vegetales en la región del Paisnal.

A fin de avanzar en su desarrollo nos parece que es importante replicar algunas experiencias en la totalidad de las comunidades o, en todo caso, en la mayoría, si las condiciones materiales no lo posibilitaran hacerlo en todas.

4.1 Así tenemos que sería de suma importancia crear comités de comercialización o de compra-venta que realizaran compras de insumos de manera coordinada con varias comunidades, como un primer paso 
hacia la creación de una proveedora de insumos agropecuarios que abasteciera a todas las comunidades de un municipio o de una región. Esto permitiría obtener mejores precios de compra y en el segundo caso, además de los precios generar empleo y retener cierta masa de excedente en el sector comunitario. De igual manera sería importante realizar las ventas de productos de manera asociada y procurando los mejores precios posibles. Muchas comunidades realizan la venta de sus productos a "coyotes" que llegan a la comunidad o bien de manera individual en los mercados de las ciudades vecinas, lo cual obviamente les desfavorece. En el caso del maíz, por ejemplo, resulta interesante cómo algunas comunidades han eliminado a los intermediarios y venden directamente a quienes se dedican a producir tortillas o pupusas, lo cual posibilita que tanto el productor como el comprador logren un mejor precio.

4.2 Es necesario también avanzar en la diversificación de la producción agrícola y preservar la producción de granos básicos sólo para el autoconsumo, así por ejemplo, algunos cultivos que han resultado ser exitosos son el loroco, el añil, el maní, el ajonjolí. O frutales como: marañón, aceituno, naranjos, limones, mangos, etc. $\mathrm{O}$ bien, la producción de hortalizas, actividad para la que existe un mercado, ya que mucha de la hortaliza consumida nacionalmente se importa. Pero también es necesario desarrollar aún más la ganadería, la porcicultura, la cunicultura y la crianza de pollo de engorde. También es importante avanzar más hacia el procesamiento de los productos agrícolas. Ciertamente, ya existen algunos esfuerzos, ejemplo: frutas deshidratadas en Guarjila o las plantas procesadoras de San Carlos Lempa y no faltan ideas, por ejemplo, en la comunidad La Joya, piensan en ampliar sus naranjales y pasar a envasar el jugo de naranja o bien a producir queso en vez de vender la leche fluida.

4.3. En la actual fase de desarrollo de las comunidades es de suma importancia la búsqueda de apoyos técnicos, tanto para la producción agroindustrial como para la comercialización. Algunos ejemplos. En varias comunidades del país se cuenta con árboles de aceituno; sin embargo no se está procesando la semilla. Sería conveniente buscar asesoría técnica para su procesamiento, lo mismo puede decirse para el jiquilite, el cual tiene buen precio internacional. O para el envasado de frutas, para la elaboración de jugos de mango, de naranja, etc. 
4.4 También sería conveniente explorar la posibilidad que tienęn las plantas procesadoras de San Carlos Lempa de ampliar su producción, de manera que muchas comunidades de la zona de Tecoluca pudieran abastecer de leche, de semilla de marañón, de maní, o de hortalizas a talas plantas.

4.5 Consideramos también que sería conveniente para diferentes grupos de comunidades de una misma región aprovechar la organización regional existente con fines económicos o crear asociaciones semejantes a la del Sistema Económico Social del sur de Tecoluca. La experiencia acumulada por el mismo debería de ser aprovechada en otras regiones del país. Adicionalmente, ello posibilitaría crear proyectos de mayor envergadura y beneficiar a un mayor número de personas. Las familias conocen ya los beneficios que brinda la asociatividad a nivel de comunidad. Ahora es importante avanzar hacia la asociatividad entre las comunidades con fines económicos. Han comprobado también las ventajas de la asociatividad cuando se trata de tener acceso agua potable, a energía eléctrica, etc. Ahora deben hacerlo en el campo económico: en la producción y en la comercialización de lo producido.

4.6 Adicionalmente, en la mayoría de comunidades existen problemas en cuanto a las unidades de salud. Muchas tienen locales, pero no tienen medicamentos, ni médicos. No obstante, existe conocimiento en cuanto a medicamentos de origen vegetal, así como también una pequeña planta que procesa y envasa los mismos, en la comunidad Rutilio Grande, me parece que si se realizara una campaña en todas las comunidades organizadas, promoviendo este tipo de medicamentos y adicionalmente se capacitara a promotores de salud en el uso de los mismos, no sólo se podría expandir la planta existente, sino que se estaría dando un paso muy importante en cuanto a enfrentar de manera alternativa las necesidades de medicamentos, lo cual es beneficioso en términos económicos $\mathrm{y}$ de salud. $\mathrm{Y}$ adicionalmente se estaría estableciendo una vinculación económica entre las diferentes comunidades y no se dejaría escapar parte del excedente generado en las mismas, cuando las personas tienen que ventas comerciales de medicamentos tradicionales.

4.7 Otro punto de suma importancia de alcanzar es la articulación económica de las comunidades entre sí, antes que con el mercado 
capitalista, ya que de esta manera se retendría el valor agregado generado en las comunidades y no se transferiría al sector capitalista de la economía. Ciertamente, es imposible desconectarse totalmente de los circuitos capitalistas; sin embargo, es posible disminuir los vínculos. ¿Cómo hacerlo? Ciertamente no resulta sencillo, pero lo primero que se requiere es conocer qué produce cada comunidad y dónde se abastece de lo que no produce, de manera que pudiera ser abastecida por el mismo sector comunitario. Lo segundo sería promover la diversificación y la especialización productiva, a fin de que las comunidades de una región o municipio pudieran abastecerse entre si. Lo cual nos estaría indicando que es importante producir aquello que la misma gente compra.

4.8 También consideramos sumamente importante el avanzar de la agricultura hacia la manufactura, esto es, a producir aquellos bienes de consumo que los mismos habitantes de las comunidades demandan: ropa, calzado, utensilios de cocina, jabón de semilla de aceituno, utensilios de trabajo: cumas, machetes, chuzos, etc., así como semilla mejorada, abono e insecticidas orgánicos, etc.

4.9 Lo anterior no debe de verse como excluyente en cuanto a la producción para el mercado capitalista, ya sea nacional o internacional; sin embargo, aquí es preciso considerar a qué nichos del mercado es posible tener acceso, o bien, si se cuentan con los niveles de productividad tal, que permitan vender con beneficios en un ámbito tan competitivo como es el mercado capitalista, cual es el caso de las plantas del Sistema Económico Social en el sur de Tecoluca, cuyos niveles de productividad resultan ventajosos.

4.10 Otro tema en el cual se debe de avanzar es el de la creación de un sistema financiero popular que elimine los vínculos con la banca comercial, de tal manera que los beneficios que genera esta actividad se queden dentro del sector comunitario. Pero, adicionalmente, que posibilite el acceso al crédito a muchas comunidades y que, a su vez, lo haga en condiciones menos onerosas. La realidad nos indica que en muchas comunidades existen bancos comunales o cooperativas de ahorro y crédito, si estos esfuerzos se sumaran y se concentran en una sola institución se podría crear una financiera popular comunitaria.

4.11 Nos parece también que es necesario que las diferentes comunidades socialicen sus experiencias, tanto positivas como negativas, de 
tal manera que las mismas puedan ser aprovechadas por todos. Para ello, quizás, debería de realizarse un Foro Comunitario Nacional con representantes de las diferentes comunidades, el cual podría servir además para establecer contactos de carácter comercial entre las diferentes comunidades.

4.12 También es importante dar a conocer y promover la visita a aquellos lugares de carácter turístico entre nacionales y extranjeros que se sienten identificados con estas experiencias comunitarias. Así por ejemplo: El centro turístico de la comunidad Las Américas en la calle a Suchitoto, donde, además de disfrutar de las piscinas, se puede comer camarón de río cultivado en la misma comunidad; o el hotelito Armonía en San Antonio Los Ranchos; o el museo de la revolución en La Sabana, cerca de Tecoluca, etc.

4.13 Consideramos también que las ONG involucradas en el desarrollo comunitario, particularmente CRIPDES y CORDES, deberían de contar con departamentos especializados en el estudio, diagnóstico de potencialidades, formulación de proyectos económicos y entorno económico nacional, a fin de proveer asesoría a las comunidades en materia económica, ya que el desarrollo económico de las comunidades es lo que puede garantizar su desarrollo sostenible en el tiempo.

4.14 Nos parece que sería útil continuar con estos trabajos de investigación, de tal manera que a un plazo lo más corto posible, se pueda contar con un diagnóstico de todas, o al menos, de la gran mayoría de comunidades organizadas. Ello no sólo nos indicaría las carencias en el ámbito social de cada comunidad, sino que a su vez posibilitaría la coordinación de esfuerzos en materia económica, así como también crear y desarrollar los intercambios comerciales intercomunitarios. La gran ventaja de conseguir lo anterior es que se podrían ir cerrando las cadenas de valor agregado en las comunidades y el excedente generado en las mismas no se escaparía hacia el sector capitalista de la economía. Lo cual, a su vez, estaría posibilitando crear un eje de acumulación y crecimiento dentro del sector comunitario. Esto es pasar de un modelo de crecimiento extrovertido (compraventas al sector capitalista) hacia un modelo de crecimiento endógeno (compra-ventas intercomunitarias). Todo ello se traduce en la posibilidad de generar mayores puestos de trabajo al interior de las comunidades, lo cual se traduce en incrementos de ingresos entre las familias comunitarias, las cuales a su vez demandarían más productos comuni- 
tarios, lo que exigiría incrementar la producción y con ello el empleo y los ingresos, etc. Este es un círculo virtuoso de desarrollo.

4.15 Es necesario ampliar el apoyo a las comunidades organizadas, así como promover la organización de aquellas que aún no lo están, particularmente por aquellas instituciones que se definen a favor del cambio social o que manifiestan una opción preferente por las mayorías populares.

4.16 La cantidad de recursos humanos con que cuenta nuestra universidad, por ejemplo, en términos de horas sociales de nuestros miles de estudiantes, y que podrían emplearse de manera productiva apoyando de manera sistemática a las comunidades, es tal, que me parece necesario y urgente avanzar mucho más en este sentido. Ello no sólo beneficiaría a las comunidades, sino que también a los estudiantes de nuestra universidad. Me parece que lo anterior sería una forma bella de convertir en realidad nuestro visión y compromiso como universidad.

\section{Perfil de las comunidades estudiadas}

La razón de incluir este apartado es para que quienes están interesados en el ámbito del desarrollo comunitario puedan tener una idea de conjunto y rápida de la realidad de las comunidades estudiadas. Ciertamente, mucha de la riqueza encontrada en los trabajos de campo realizados por los estudiantes se queda fuera, pero el volumen de páginas que significaría reproducir 51 trabajos, sencillamente lo haría impublicable como un artículo. Adicionalmente, este escrito tiene por objetivo responder de alguna manera a la colaboración brindada por el personal de CRIPDES, particularmente, a Marcos Gálvez, su presidente. Deseamos finalmente aclarar que si bien los estudiantes trabajaron en base a una guía metodológica proporcionada por nosotros, no todos reportaron la información que se les solicitaba, por las diferentes razones que fueran, de allí que la información sobre algunas comunidades esté incompleta. Sin embargo, téngase en cuenta lo complicado de coordinar una investigación realizada por 300 personas.

\subsection{Departamento de Cuscatlán, municipio de Suchitoto}

Suchitoto posee 77 comunidades que surgen luego de los acuerdos de paz, de ellas sólo se visitaron algunas. 


\section{'1. Pepeistenango}

-36 familias.

- Casas mayoría en buen estado, construidas en lotes de 2,500 varas cuadradas.

- Cuentan con escuela hasta 9 grado, energía eléctrica, casa comunal, agua (proyecto en ejecución),

- Disponen de $100 \mathrm{mz}$. arrendadas, cultivan maíz, frijol, ajonjolí, pipián, sandía y melón.

- Ganado en propiedad comunitaria.

- $25 \%$ de las personas en edad de trabajar lo hace fuera de la comunidad.

- Proyecto de Clínica en conjunto con Agua Caliente y Copapayo.

- Se encuestó a 23 familias.

\section{Copapayo}

- 160 familias.

- Casas con agua y electricidad.

- Escuela hasta 8 grado, tienen también guardería.

- Clínica (sólo el local)

- Cuentan con tierra donde cultivan: maíz, frijol, pipianes y ayotes.

\section{Agua Caliente}

-67 familias.

- Poseen clínica pero no personal ni medicinas, escuela hasta $7^{\circ}$ grado.

- Energía eléctrica, banco comunal, casas propias en $0.25 \mathrm{mz}$.

- Tierra para cultivos $3 \mathrm{mz}$. por familia.

\section{Milingo}

- 125 familias.

- Tierras para cultivo $26 \mathrm{mz}$. 
- Comunidades aledañas: Las Américas, Cablote y Bermudas. Trabajan juntas en búsqueda de proyectos.

- Tienen agua potable y pagan 40 colones mensuales, también energía eléctrica, ambos proyectos los han logrado en conjunto con las otras comunidades.

- Escuela hasta 9 grado. Poseen cancha de fútbol.

- Cultivan: maíz, maicillo, frijol y ajonjolí.

- Tierra para cultivos $5 \mathrm{mz}$. por familia, $0.25 \mathrm{mz}$. lote para casas.

- Iglesia en proceso de construcción.

- Participa en proyectos con otras 12 comunidades.

\section{Las Américas}

-200 familias.

- Asociación cooperativa dedicada a producir camarón de agua dulce.

- Proyecto turístico Las Américas, con dos piscinas, chalet y rancho, funcionando.

- Otras actividades económicas: cultivo de maíz y frijol. Confección de ropa y calzado. Artesanías, piñatas y bordados.

- Cuentan con casas propias y tierras para cultivos.

- Disponen de agua potable, energía eléctrica y escuela hasta 9 grado.

- Aproximadamente $25 \mathrm{mz}$. están destinadas a proyectos comunitarios.

- Cuentan con un camión y un pick up.

- Tienen un conjunto musical.

- Proyecto: Huertos caseros de hortalizas.

\section{Comunidad Marianela}

Fundada en 1989, su nombre es en honor a Marianela García Villa

-54 familias.

- Poseen parcelas para sus cultivos, viviendas en mal estado. 
- Tienen un comité de comercialización, junto a otras 7 comunidades, el cual se encarga de buscar los mejores precios de compra de insumos y venta de sus productos.

- Escuela hasta $6^{\circ}$ grado, funciona con el programa EDUCO, tienen cancha de fútbol. Gobierno paga tres maestros de los seis.

- Poseen casa comunal, agua potable, clínica con enfermera y equipo medico, también medicinas.

- Usan barreras vivas para proteger el suelo de la erosión, han destinado 6 _ mz. a área forestal.

— No está legalizada la propiedad.

\section{Santa Eduviges}

-11 familias

- Poseen $5 \mathrm{mz}$. por familia.

- Casas en buen estado con energía eléctrica, cuentan con casa comunal.

- Cultivan maíz, maicillo, anís y cacahuete. Afectados por los bajos precios.

- Tienen proyecto de agua potable con otras 7 comunidades: Las Moras, Los Almendros, Haciendita 1 y 2, Masatepec, Nueva Concepción y Apolinario.

— No tienen escuela pero existe una cerca de la comunidad.

\section{Nueva Consolación}

- 29 familias, la mitad tiene casas en buen estado.

- Poseen tierras entre 2 _ y $3 \mathrm{mz}$. por familia.

- Cultivan: maíz, maicillo, frijoles, ajonjolí, caña de azúcar y sandías.

- Poseen graneros.

- Cuentan con agua potable, energía eléctrica, local para clínica, casa comunal, bodega y cancha de basketball, escuela hasta $3^{\circ}$ grado.

- Se trata de una comunidad bastante aislada. 


\section{Laura López}

- Nombre en recuerdo de catequista asesinada durante la guerra.

- 78 familias

- Cuentan con escuela hasta $6^{\circ}$ grado, bajo el programa EDUCO, energía eléctrica, local para clínica y promotora de salud.

- Casas en regular estado en lotes de $1600 \mathrm{~m}^{2}$.

- Tienen tierras donde cultivan: maíz, frijol, caña de azúcar, sandía, ajonjolí y pipianes; venden a coyotes.

- Tienen un pickup.

- Algunas familias reciben remesas.

- En proyecto el servicio de agua potable.

10. San Antonio El Barío, fundada en 1986.

- 150 familias

- Poseen una cooperativa.

- Existe una asociación de mujeres

- $80 \%$ de viviendas en buen estado, cuentan con agua potable y energía eléctrica.

- Clínica de salud y asistencia odontológica.

- Sistema educativo cubre desde kinder hasta bachillerato.

- Cuentan con casa comunal y parroquia.

- Disponen también de un plan de becas para estudiar en la universidad.

- Jóvenes participan en cursos de capacitación en Suchitoto en las áreas de carpintería, albañilería y electricidad.

\section{El Papaturro}

\section{- 74 familias}

- Además de la organización comunitaria poseen una cooperativa de ahorro y crédito. 
- Cuentan con casas en buen estado, con agua potable, energía eléctrica, casa comunal, escuela y clínica.

- Cultivan: maíz, frijol y caña de azúcar.

- Realizan obras de conservación de suelos: barreras vivas y muertas, también están reforestando las orillas de las quebradas.

- Las mujeres realizan artesanías: aretes de semilla de pacún.

\section{El Chaguitón}

- 36 familias (religión evangélica)

- Sus viviendas están en buen estado la mayoría, poseen energía eléctrica y agua potable.

- Tienen kinder y escuela.

- Tierra para cultivos, entre 4 y $5 \mathrm{mz}$. por familia, cultivan maíz, frijol, caña de azúcar y cacahuete.

- Poseen motor y bomba para riego.

\subsection{Departamento de Chalatenango, región nororiental}

\section{Nueva Trinidad}

- Casco urbano: 57 familias

— Viviendas, $90 \%$ en buen estado, poseen agua potable y energía eléctrica.

— Todas las familias poseen tierra pero nadie puede tener más de 6 mz.

- Cultivan maíz, frijol y maicillo. Agricultura orgánica, realizan labores de reforestación y conservación de suelos.

- Clínica con médico, equipo y medicamentos básicos.

- Escuela hasta $9^{\circ}$ grado.

- Poseen tienda, comedor y ganado en propiedad comunal.

- Los sábados es un día comunal, en el cual se realizan trabajos de beneficio para la comunidad. 


\section{Carasque}

- Pertenece al municipio de Nueva Trinidad, repoblado en el 92.

-58 familias

- Viviendas un $60 \%$ en buen estado, $25 \%$ regulares. Solares de $1 \mathrm{mz}$.

- Poseen energía eléctrica y agua domiciliar, pero no es apta para beber porque es ácida. Para el consumo tienen pozos.

- Area de salud, poseen 2 parteras y 2 promotoras de salud.

- Educación, programa EDUCO, hasta $9^{\circ}$ grado. Cancha de fútbol.

- Guardería, niños de 2 a 6 años, de 7a.m. a 4 p.m., por cincuenta centavos diarios se cuida a los niños, se les da alimentación y chequeo médico.

- Por las noches se da educación a los adultos, asisten 20 personas.

- Se cuenta con una miniblioteca y un pequeño centro de computación, donde se adiestra a jóvenes en el manejo de computadoras por un colón cincuenta la hora, para darle mantenimiento a los equipos.

- Además de la organización comunitaria, se tiene una cooperativa.

- Tienen casa comunal.

- Cuentan con un camión Mercedes Benz.

- 15 madres solteras y 6 viudas reciben ayuda de la comunidad.

- Cultivan: maíz, frijol, arroz, café, ajonjolí y hortalizas. Usan abono orgánico.

- 90\% de las familias tienen ganado, entre 4 y 15 cabezas por familia.

- Existen $60 \mathrm{mz}$. comunitarias, de las cuales 10 se reforestarán, pensando en crear a futuro un centro turístico en medio del pinar, así como también un taller de bordado e incrementar la producción y exportación de café procesado a los E.U. De las familias de Carasque, un $70 \%$ recibe remesas y existe una comunidad organizada de los migrantes en los Estados Unidos, quienes envían cada mes una cantidad de dólares a la directiva para que esta los asigne a la familia más necesitada. Son estos contactos los que piensan que les permitirá incrementar la exportación de bordados y café procesado a los Estados Unidos, ahora lo hacen pero en pequeña escala. 


\section{Arcatao}

- Entre 250 y 300 familias en el área urbana.

- Las viviendas en su mayoría están en buen estado, poseen agua potable y energía eléctrica.

- Cuentan con clínica y educación hasta bachillerato.

- Además de la organización comunitaria, poseen una cooperativa agropecuaria y ganadera Ruperto Castro.

- Existen 2 minibancos comunales, uno exclusivo de las mujeres, tiendas comunales, comedor comunal, talleres-escuela comunales: metal mecánica, bordados, panadería, carpintería y sastrería.

- Oficina de Telecon y una farmacia, destacan como propiedades privadas.

- Existe puesto de la PNC y juzgados de paz.

- Poseen vehículos comunales y ganado vacuno y caballar

- Están en proceso de diversificación agrícola, introduciendo mango, naranjo y limones. Cuentan con una planta deshidratadora de frutas, proyectan exportar producto disecado.

- La gran mayoría es católica y la parroquia es atendida por los jesuitas. Un pequeño sector evangélico no comparte la visión comunitaria

\section{Teosinte}

Pertenece al municipio de Arcatao

-210 familias

- Viviendas fueron dañadas por terremoto, poseen energía eléctrica y agua, pero ésta la reciben cada tres días.

- Tienen un dispensario y reciben las visitas de un médico cada semana.

- Escuela hasta $9^{\circ}$ grado.

- Cultivan maíz y frijol. La tierra es insuficiente, tienen que arrendar. Urgen de créditos. 


\section{San José Las Flores}

- Alrededor de 500 familias

- El $80 \%$ de las viviendas se encuentran en buen estado, cuentan con agua potable, energía eléctrica y algún teléfono.

- Cuentan con dos clínicas y varios promotores de salud. Servicio odontológico.

- Tienen guardería, kinder, escuela e instituto.

- Poseen tiendas, telar, comedor y panadería comunales.

- Además de la organización comunitaria, cuentan con una cooperativa.

- Existe un banco comunal de las mujeres.

- Su actividad principal es la agricultura y ganadería.

- (Nos parece que la información es incompleta)

\section{San Antonio Los Ranchos}

Repoblado en 1987.

-300 familias

- Viviendas, un $80 \%$ en buen estado, poseen agua potable y energía eléctrica.

- Existe una unidad de salud y los visitan médicos de Chalatenango.

- En el área de educación: guardería, escuela e instituto.

- Casa comunal y servicio telefónico.

- La comunidad posee ambulancia, un camión y un pick up.

- Cada familia tiene parcelas propias de $1.5 \mathrm{mz}$.

- Se dedican al cultivo de granos básico, hortalizas y ganadería. Emplean abono orgánico, realizan conservación de suelos y reforestación.

- Otras actividades económicas: alfarería, zapatería, confección de ropa bordada, carpintería, 2 comedores y un pequeño hospedaje, llamado Hotel Armonía, el cual es un proyecto de los jóvenes, 
quienes además lo ven como un espacio experimental y ecológico. Para cocinar se usa gas metano generado por el estiércol de cerdos.

- Se busca implementar el uso de cocinas solares y el cultivo de plantas medicinales.

\section{Guarjila}

Repoblada en 1987.

- Aproximadamente 400 familias.

- Las viviendas en su mayoría están en buen estado, cuentan con agua potable y energía eléctrica.

- Poseen una clínica y farmacia comunitaria. Cuentan con un seguro familiar de salud, mediante el pago de 15 colones mensuales reciben atención médica y medicamentos.

- Guardería, kinder y escuela hasta $9^{\circ}$ grado. El instituto de San Antonio Los Ranchos está muy cerca.

- Además de la organización comunitaria, poseen una cooperativa ganadera.

- Se dedican al cultivo de granos básicos, pero poseen también tiendas, taller de costura, de carpintería y un comedor comunal. Tres pequeñas deshidratadoras de frutas.

- La comunidad tiene una radio comunitaria: Radio Sumpul que transmite en 92.1 FM

— Sigue pendiente la legalización de algunas tierras.

\section{San Isidro Labrador}

- Aproximadamente 400 familias, (el municipio, supongo)

- Viviendas con agua potable y energía eléctrica.

- Unidad de salud con doctor y enfermera.

- Escuela hasta $6^{\circ}$ grado, bajo el programa EDUCO.

- Casa comunal y servicio de Teléfono.

- Tierras de la comunidad y familias.

- Cultivan granos básicos y hortalizas. 


\section{3. Comunidades del departamento de San Vicente, municipio de Tecoluca.}

\section{La Sabana}

Se crea, vía programa de transferencia de tierras, PTT.

- 80 familias, $25 \%$ de familias tienen un lisiado de guerra.

- Poseen agua potable y el $95 \%$ de viviendas se encuentra en buen estado, área de solares $0.25 \mathrm{de} \mathrm{mz.}$

- Cuentan con casa comunal, kinder y escuela hasta $6^{\circ}$ grado.

- La comunidad dispone de $505 \mathrm{mz}$ de tierra, para actividades agrícolas y ganaderas.

- Cuentan con un proyecto de elaboración de flores y piñatas, así como otro para la elaboración de prótesis.

- Destacable de esta comunidad es la participación de la mujer, de las 400 que integran la Asociación Rural de Mujeres, una cuarta parte son de La Sabana.

- También merece destacarse su preocupación por preservar la memoria histórica, en tal sentido en lo que era la antigua casa patronal en el caso de la hacienda, han creado un museo de la revolución.

- Las necesidades crediticias las resuelven a través de la cooperativa El Roble, ubicada en San Carlos Lempa y que es parte del Sistema Económico Social.

\section{Monte Sinaí}

Es una repoblación efectuada en 1998.

-60 familias.

- La condición de las viviendas es buena y son recién construidas en lotes de $10 \times 25 \mathrm{~m} 2$.

- Cuentan con agua potable propia, sólo pagan 7 colones mensuales, también cuentan con energía eléctrica.

- Disponen de tierras, entre 3 y $5 \mathrm{mz}$ por familia, pero están distantes $5 \mathrm{kms}$. de la comunidad.

- Su principal actividad es la agricultura. 


\section{El Socorro}

Repoblación efectuada en 1992, PTT.

- 48 familias

- Cuentan con agua potable y energía eléctrica.

- Escuela funciona hasta $6^{\circ}$ grado, bajo el programa EDUCO.

- Además de la organización comunitaria, cuenta con una cooperativa.

- Tienen un banco comunal.

- Se dedican a al cultivo de maíz, maicillo y ajonjolí.

\section{El Porvenir}

- 39 familias

- Viviendas en buen estado, cuentan con agua.

- Cada familia tiene parcelas entre 2.75 y $3.5 \mathrm{mz}$.

- Escuela hasta $6^{\circ}$ grado, tienen un promotor de salud.

- Se está buscando crear un fondo comunitario con el aporte de 15 cols. mensuales por familia.

- El sueño del presidente de la comunidad es la creación de una directiva a nivel de las comunidades.

\section{El Milagro}

- 107 familias aproximadamente.

- Viviendas con energía eléctrica en lotes de $18 \times 20 \mathrm{~m} 2$.

- Cuentan con kinder y escuela hasta $6^{\circ}$ grado, con programa EDUCO.

- Disponen de tierras pero fuera de la comunidad.

\section{San Francisco Tehuacán}

Repoblación efectuada en 1995.

-85 familias 
- Cuentan con taller de zapatería y artesanías.

- Agua potable.

- (Información incompleta)

\section{Guajoyo}

\section{Creada en 1992}

\section{-115 familias}

- Cuentan con 70 viviendas buenas, 19 dañadas y 25 en pésimo estado, los lotes son de $10 \times 10 \mathrm{~m} 2$.

- Cuentan con agua y energía eléctrica.

- Tienen el Centro Escolar Ignacio Ellacuría, que sirve hasta $7^{\circ}$ grado, bajo el programa EDUCO. Cancha de basquetball.

- Disponen de $900 \mathrm{mz}$. de tierra, de ellas destinan 252 a bosque de madrecacao.

- Labores agrícolas, el ajonjolí principal producto, pero los precios cayeron de 34.29 dólares el quintal a sólo 9.14, lo cual lo hace incosteable.

- Ante el problema del alcoholismo se ha creado un grupo de AA.

\section{San Francisco Angulo}

Repoblación bajo el PTT

- 78 familias

- Cuentan con energía eléctrica.

- Casa comunal y escuela hasta $6^{\circ}$ grado.

- Está en proceso de construcción la unidad de salud.

- Cada familia cuenta entre 2 y $3 \mathrm{mz}$. de tierra.

\section{Montecristo (isla de)}

Repoblación bajo el PTT

-27 familias

- Viviendas en buenas condiciones 
- Sus actividades económicas: maíz, algo de ganado y pesca. Pero la principal actividad es la marañonera, cuyo quintal de semilla venden a 200 colones, a la planta ubicada en San Carlos y que es parte del Sistema Económico Social, al cual pertenece la comunidad Montecristo. También producen vino artesanal del falso fruto del marañón. Cuentan también con un pequeño complejo turístico ecológico.

- Tienen suficiente tierra, se consideran alrededor de $800 \mathrm{mz}$. pero no todos los propietarios viven en la comunidad.

- Tienen escuela.

- No cuentan con agua potable servida, sino que se auxilian de pozos, tienen en proyecto llevar la energía eléctrica hasta la isla.

\section{San Bartolo}

Fundada en 1992, bajo el PTT.

Se encuentra muy próxima con las comunidades de El Porvenir, Santa Marta, La Sabana y Rancho Grande.

Fueron muy afectados por el huracán Micht.

-85 familias

- Cuentan con $557 \mathrm{mz}, 3 \mathrm{mz}$. por familia, $30 \mathrm{mz}$. área forestal y 5 mz. área social.

- Tienen casa comunal, kinder y escuela.

- Se dedican a la agricultura, la ganadería y a producir carbón.

- Cuentan con un pick up.

- Resulta interesante que en esta comunidad el comité de educación ha logrado conseguir: una cantidad de equipo de fotografía, de filmación y de computación. Así como televisores, vhs, refrigeradora y microndas.

- Cuentan con radio interactiva.

- Reciben ayuda de migrantes radicados en Sacramento, California. 


\section{El Casino}

Funda en 1990, en tierras propiedad del ISTA.

-78 familias

- Sufrieron los impactos del terremoto y aún no se recuperan.

- La situación es calamitosa, sólo 14 casas tienen agua, 28 viviendas no está legalizada la propiedad. No disponen de servicios de energía eléctrica, de educación, ni de salud.

\section{San Carlos Lempa}

Comunidad repoblada en 1989.

-200 familias

- 80 de las viviendas son propiedad de las familias, cuentan con agua, energía eléctrica. A quienes aún no poseen viviendas se les conseguirá en función de las necesidades y de la participación comunitaria y se construirán bajo el sistema de ayuda mutua.

- Cuentan con parque, casa comunal, servicio telefónico, puesto de la PNC.

- Disponen de $200 \mathrm{mz}$ de tierra para sus actividades agrícolas y ganaderas.

- Tienen escuela hasta $9^{\circ}$ grado, Centro de Desarrollo Infantil, para niños en edad preescolar, se les da alimentación y el servicio es gratuito.

- Existe Unidad de Salud atendida por el gobierno.

- La organización es bastante buena y participa la mayoría de la población católica, los evangélicos se excluyen.

- El Comité de jóvenes, cuenta con coordinadores de danza, teatro y comunicaciones. Lo destacable es que en una comunidad rural se realice este tipo de actividades.

- El Comité de deportes, coordina dos equipos de fútbol y uno de softball.

- En el Centro Cultural "Anastacio Aquino", además de contar con una biblioteca aceptable, se emprenden otra serie de actividades culturales. 
- En esta comunidad también se encuentran localizadas varios proyectos del Sistema Económico Social, del cual es parte integrante la comunidad San Carlos, junto a 17 comunidades mas:

- La planta procesadora de leche orgánica con alta tecnología que producirá para el mercado nacional: quesos gourmet, yogur y crema.

- Planta de acopio y embalaje de hortalizas.

- La Planta SAMO que procesa y envasa semilla de marañón, ha venido exportando a Europa, proyecta penetrar en el mercado nacional. También procesa y envasa maní. Igualmente se procesa y envasa jalea y jugo de marañón, así como marañones en almíbar.

- Se está construyendo un Polígono Industrial, para capacitar y dar empleo a los jóvenes.

- Cooperativa El Roble que atiende a varias comunidades de la zona, además de las que conforman el Sistema Económico Social, (SES).

4.4. Comunidades del departamento de San Salvador, municipios de Aguilares y El Paisnal.

\section{Dimas Rodríguez}

Se funda en 1992 bajo el PTT

-26 familias

- Viviendas en buen estado con energía eléctrica.

- Educación hasta $5^{\circ}$ grado.

- Comunidad posee $3 \mathrm{mz}$. de tierra.

- Poseen molino y panadería comunal.

-5 jóvenes de la comunidad estudian bachillerato, son becados por UCRES.

- Se prohibe la crianza de cerdos y tienen serios problemas con el agua. 


\section{La Joya}

Se funda en 1993 bajo el PTT. Esta comunidad más Nueva Jerusalén, Auxel, Nance Amarillo y La Hacienda, se encuentran muy próximas e integradas por desmovilizados del FMLN y de la FA, cual es el caso de La Hacienda. Todas se ubican en el cantón El Tronador.

-14 familias

- Viviendas en buen estado, agua potable, energía eléctrica y servicio de aguas negras.

- Inicialmente poseían $130 \mathrm{mz}$ en forma comunitaria, pero en 1998 el gobierno obligó a la parcelación. Ahora sólo poseen $30 \mathrm{mz}$ en forma comunitaria.

- Cultivan naranjas y poseen 50 cabezas de ganado.

- Una represa que sirve para regar el naranjal en verano.

- Cuentan con una cooperativa de ahorro y crédito.

- Tienen casa de salud, molino y una guardería.

- Niños estudian en escuela de El Tronador, comunidad muy próxima.

- Sus proyectos:

- Avanzar a la producción de jugo de naranja y de queso.

- Iniciar cultivo de peces en el embalse.

- Ampliar el área de riego y el naranjal.

- En lo inmediato coordinar con otras comunidades la venta de leche, a fin de obtener mejores precios.

- A juicio de los estudiantes que visitaron esta comunidad: Los valores que se fomentan, como su forma de vida y aspiraciones son muy diferentes a los de una sociedad capitalista como la nuestra.

\section{Nueva Jerusalén}

-10 familias

- Viviendas en buen estado mixto y adobe, algunas tienen energía eléctrica, poseen letrinas aboneras y agua potable. 
- En materia de salud cuentan con 3 promotores de salud, visitas mensuales de un médico y un botiquín.

- Escuela que atiende a los niños del resto de comunidades que integran el cantón El Tronador, de 1 a 9 grado

- No tienen tierra para cultivos.

\section{Auxel}

-37 familias

- Viviendas en buen estado, cuentan con energía eléctrica, no tienen agua domiciliar.

\section{La Hacienda}

-10 familias

- Tienen viviendas en buen estado y servicio de energía eléctrica.

$-3 \mathrm{mz}$. por familia para cultivos.

\section{Rutilio Grande}

Repoblación efectuada en 1991, luego de vivir 10 años en Nicaragua.

-63 familias

- Viviendas en buen estado, lotes de $11 \times 27 \mathrm{~m} 2$, poseen agua potable, energía eléctrica y letrinas aboneras. Todo es propiedad de la comunidad.

- Cada familia posee una mz. de tierra para sus cultivos.

- Centro escolar de 1 a $6^{\circ}$ grado. Gobierno no paga profesores.

- Centro de bienestar infantil, niños hasta 6 años, reciben cuido, alimentación, horario de 6 a.m. a 3 p.m., se pagan 10 colones mensuales.

- Cuentan con casa comunal y radio comunitaria, (sistema de alto parlantes).

- Comité de jóvenes se encarga del molino, de sastrería (7 máquinas), de granja de pollos de engorde y de radio. 
- Disponen de una clínica, atendida por un promotor de salud y los medicamentos son gratuitos.

- Poseen la producción artesanal de medicamentos botánicos y producen ungüentos, jarabes y cápsulas.

- Equipo e infraestructura para panadería.

- Cultivan maíz, frijol, maicillo, pepino, loroco y naces. Una familia posee ganado.

- En tierras comunales se ubica la cancha de fútbol y el jardín botánico.

- Brigadas infanto-juveniles se encargan de mantener limpia la comunidad y cada niño tiene asignado un arbolito, el cual debe de regar en verano para que no se seque.

- No hay maras ni delincuencia, los jóvenes tienen de que ocuparse.

\section{Araditas}

Fundada en 1996

-22 familias

- Viviendas algunas en regular estado, otras en pésimo estado, cuentan con agua y energía eléctrica.

\section{El Buen Pastor}

Fundada en 1989

-14 familias

- Viviendas en buen estado cuentan con agua y energía eléctrica

- Tienen escuela, casa comunal, local para clínica, instalaciones para un gallinero y un camión.

- Cultivan maíz, frijol y hortalizas.

- Cada familia cuenta con una vaca.

- Están organ1izados, además de la asociación comunal, en cooperativa. 
4.5 Comunidades del departamento de La Libertad, municipios de Tamanique, Tacacbico, Chiltiupan y Comasagua.

- Tamanique:

\section{Tarpeya}

- 71 familias

Fueron afectadas por el terremoto y poseen casas de lámina sin ningún servicio. No tienen agua, ni energía, ni escuela.

\section{Loma Linda}

- 46 familias

Han recibido ayuda luego del terremoto.

Ya poseen energía eléctrica, pero agua todavía no.

Poseen sólo el terreno para escuela y casa comunal.

Serio problema de alcoholismo y de analfabetismo.

\section{El Progreso}

\section{Damnificados por El Mitch}

No tienen viviendas dignas, ni servicio de agua, aunque sí energía eléctrica. bol.

Cuentan con dos aulas provisionales y un terreno para jugar fút-

- Tacachico:

\section{Ita Maura}

La comunidad se funda con repatriados de Honduras a principio de los 90s.

- 59 familias

- Las viviendas se encuentran en buen estado, poseen agua y energrá eléctrica. 
- Poseen escuela hasta $9^{\circ}$ grado, funcionan bajo el programa EDU$\mathrm{CO}$, disponen de 3 maestros populares.

- Cuentan con casa comunal, guardería y clínica con 4 promotores de salud.

— Poseen $270 \mathrm{mz}$. de tierra para sus actividades agrícolas, además de un tractor.

\section{San Jorge}

Se trata de una repoblación.

-67 familias

- Viviendas en buen estado y cuentan con energía eléctrica.

- Poseen escuela.

- Disponen de $1500 \mathrm{mz}$. de tierra para sus actividades agrícolas y ganaderas. $60 \mathrm{mz}$. las conservan como área forestal y tienen un vivero de $2 \mathrm{mz}$. Realizan obras de conservación de suelos.

- Cuentan con 1 tractor, 1 vehículo y un sistema de riego con motor.

- Cuando el precio de la caña de azúcar era rentable, obtuvieron un año un excedente de 100 mil colones, los cuales distribuyeron entre los miembros de la comunidad.

- En la actualidad la producción agropecuaria la están vendiendo a intermediarios.

- Algunos miembros de la comunidad desean parcelar.

\section{San José Las Arenas}

Se trata de un asentamiento.

- 208 familias

- Las viviendas están en buen estado, cuentan con energía eléctrica y agua potable la mayoría.

- Tienen escuela hasta $9^{\circ}$ grado.

- No poseen tierras para sus actividades agrícolas. 
- Se enfrentan a problemas de maras.

- Se percibe cierto desánimo.

- Chiltiupán

7. Taquillo

Se origina a raiz de la reforma agraria

- 79 familias

- Viviendas en lotes de $1 \mathrm{mz}$., poseen energía eléctrica, pero no tienen agua.

- Para sus actividades agrícolas cada familia cuenta entre 4 y $5 \mathrm{mz}$.

- Tienen una cancha de fútbol y 2 iglesias, una católica y otra protestante.

- Comasagua

8. Los Leones

-22 familias

- Se origina hace 24 años como un asentamiento ilegal, aunque posteriormente legalizan la tenencia de la tierra donde se ubican sus viviendas, las cuales se encuentran en mal estado, disponen de energía eléctrica.

- No disponen de tierras para sus labores agrícolas.

9. Bello Horizonte.

Surge a raíz del terremoto del 2001 y está en proceso de conformación.

-228 familias

- Poseen casas en buen estado, pero no disponen de agua, ni energía eléctrica, aunque ya está el tendido de cables.

- La escuela está en proceso de construcción.

- No disponen de tierras para sus actividades agrícolas. 
10. El Faro.

Su origen se encuentra en la reforma agraria.

- 90 familias.

- Las casas fueron dañadas por el terremoto, disponen de energía eléctrica pero no de agua potable.

- Escuela hasta $9^{\circ}$ grado; cuentan con el auxilio de promotores de salud y visitas ocasionales de 1 médico.

- Están organizados en cooperativa, la cual posee 73 miembros.

- Cuentan con $584 \mathrm{mz}$. de tierra, distribuidas en $265 \mathrm{mz}$. para café, $100 \mathrm{mz}$. para cultivo de granos básicos, $100 \mathrm{mz}$. para pastos, $59 \mathrm{mz}$. de reserva forestal y el resto son excesivamente quebradas.

- Disponen de 1 camión.

- Obviamente en la actualidad tienen serios problemas debido a la caída de los precios del café, lo cual los ha llevado a adeudar 2 millones de colones; sin embargo se pueden apreciar grandes potencialidades.

\section{San José Guadalupe}

Su origen se encuentra en la reforma agraria, se inician como cooperativa pero en la actualidad está quebrada.

-30 familias

- Sus viviendas fueron dañadas por el terremoto, cuentan con energía eléctrica.

- Escuela hasta $5^{\circ}$ grado.

- Cada familia dispone entre 4 y $5 \mathrm{mz}$. de tierra para sus actividades agrícolas.

- Enfrentan problemas de acceso y también para comercializar sus productos. 
Anexo: Guia metodológica.

Trabajo de investigación, grupo de 5 estudiantes.

Materia: Desarrollo Económico

Estudio empírico de una comunidad rural organizada

Elementos que debe de contener el trabajo:

1. Nombre y ubicación de la comunidad visitada.

2. Estimado de la población que la integra, número de familias.

3. Formas organizativas que tiene: asociación comunitaria, directiva, comités, cooperativa, etc.

4. ¿Cuál es la participación de la mujer en las estructuras organizativas?

5. ¿Cómo se considera la participación de la gente en actividades de la comunidad? Mucha? Poca? Regular? Poner ejemplos.

6. Servicios sociales de que gozan: salud, agua, educación, energía eléctrica, guardería, casa comunal, etc.

- ¿Propiedad de los mismos: de la comunidad, del estado o empresa privada?

- Si son propios, ¿cómo los han obtenido y cómo los mantienen?

7. Condición de las viviendas, (en porcentajes)

- Buenas (Buen estado de techos, paredes y pisos)

- Regulares (Buen estado de techos y paredes)

- Malas (Mal estado de todo)

8. Propiedades de la comunidad con fines económicos:

- Tierras son propias Si_ No__Extensión aproximada

- Maquinaria y equipo, detallar.

- Vehículos, detallar.

- Otros

9. Actividades con fines económicos que tiene la comunidad:

- Comercio (detallar) 
- Agricultura (detallar los tipos de cultivo) (Determinar si tienen prácticas agroecológicas o ecológicas. Ejemplos: agricultura orgánica, reforestación, conservación de suelos, etc.)

- Manufactura (detallar) Ejs. Artesanías, zapatos, confección de ropa, etc.

- Industria (detallar) Ejs. Bloquera, ladrillera, tejera, carpintería, etc.

- Banco comunal o cooperativa de ahorro y crédito.

- Otros: comedores, panaderías, molinos de nixtamal, etc.

- ¿Cuál o cuáles son las actividades económicas más importantes en la comunidad?

- ¿Mantienen relaciones comerciales con otras comunidades?

- ¿Dónde venden lo que producen?

10. Los habitantes de la comunidad trabajan en la misma. ¿Todos, la gran mayoría, unos pocos?

11. Las fuentes de ingresos son:

- Del trabajo en la comunidad

- Del trabajo fuera de la comunidad

- Se combinan los dos anteriores

- Remesas

- Otros

12. En sus casas tienen animales de corral: gallinas, cerdos, pavos, patos, etc.

13. En sus casas tienen cultivos frutales, hortalizas, etc.

14. ¿Cómo evalúa la comunidad sus condiciones de vida?

- Están igual

- Están mejorando

- Están empeorando

15. ¿Cuáles son los principales problemas que enfrenta la comunidad?

16. ¿Proyectos a futuro de la comunidad? 
17. ¿Organismos gubernamentales y no gubernamentales (ONG) que ayudan a la comunidad? ¿Cuáles y en qué?

18. ¿Qué impresiones traen ustedes de la comunidad visitada? ¿Qué les llamó la atención? ¿Creen que podrían ayudar en algo? ¿Cómo, en qué?

\section{Ojo: Elementos importantes a tener en cuenta:}

Buscar un informante calificado: esto es, un directivo, un líder de la comunidad, etc. alguien que tenga conocimiento de la comunidad.

a) Si encontraran cosas interesantes no incluidas en esta guía, tomarlas también en cuenta.

b) Se recomienda antes de realizar visitas de campo, leer el cap. 6 del libro de Desarrollo.

c) Tener en mente que se busca detectar si a nivel de realidad existe una estrategia popular de desarrollo que busque enfrentar los problemas de desempleo, pobreza y marginación social; así como preservar el medio ambiente.

d) Importante: La guía como su nombre lo indica es tan sólo una orientación que posibilita homogeneizar los diferentes trabajos. Pero ustedes deberán elaborar un cuestionario propio, recabar la información y procesarla, hacer cuadros, si fuera necesario, etc. Y redactar luego un informe que contenga: introducción, contenido de la investigación y conclusiones. Un anexo que contenga: la información procesada y el numeral 18 de la guía. 